\title{
Incomplete Tumor Cell Necrosis
}

National Cancer Institute

\section{Source}

National Cancer Institute. Incomplete Tumor Cell Necrosis. NCI Thesaurus. Code C156235.

A morphologic finding indicating the presence of focal or diffuse tumor cell necrosis involving part of the neoplastic cellular infiltrate in a tissue sample. Viable tumor cells are still present. 